before his mind the doctrine of natural selection. The medieval schoolmen were by no means wedded to the theory of special creation, and in the eighteenth and early nineteenth centuries the transformist view was freely canvassed, without, however, making much way among scientific thinkers. The "Historical Introduction" prefixed to the later editions of the "Origin of Species" gives an account of several anticipations, more or less exact, of the Darwinian theory.

But the present treatise goes far beyond most, if not all, previous attempts at solving the problem of evolution. The clear grasp shown by the author of the Darwinian principles of the struggle for life, and origin of fresh species by the preservation of those forms best adapted for their environment, his advocacy of the persistence of germinal characters, and the very terminology that he uses, might well suggest a doubt as to whether the pamphlet is really what it professes to be, or whether it is not, in fact, a cleverly devised fabrication with a falsified date. We find, for example, such expressions as the following:-_Life owes its faint beginning to primal germs ... pervading the entire terrestrial atmosphere; and, perhaps, the entity of the Cosmos"; "everywhere about us we see waged the pitiless battle for life ... the useless perish, the useful live and improve"; "Man and the Ape are co-descended from some primary type"; "The life germ resident in Man transmitted to his descendants goes on existing indefinitely." Here are anticipations, not only of Darwin, but also of Arrhenius, Galton and Weismann. Not less surprising are his enunciation of the germ-theory of disease, his experiments on the cultivation of streptococci from a sore throat, with the use as a germ-filter of cotton wool sterilised by heat, his suggestion of the action of phagocytes, and his recommendation of metal gauze protective frames for doors and windows in order to ward off infection carried by insects.

The question of the genuineness and authenticity of the pamphlet is carefully discussed by Prof. Poulton. The evidence on the point is perhaps not absolutely conclusive; but it may fairly be said that after weighing the interesting information brought together by Prof. Poulton respecting the book and its author, few will doubt that Mr. Sleeper's work was really printed and published at the time stated, and that it contains one of the most remarkable anticipations of modern views and forms of expression respecting evolution and the germ-theory of disease that have yet come to light.

F. A. D.

\section{THE RECENT VOLCANIC ERUPTIONS IN} JAPAN.

LTHOUGH the resulting destruction of life $A$ and property has happily been far less than was indicated by the early accounts, yet there can be no doubt that a volcanic outburst of great magnitude has taken place in Japan. The vulcanologists of Tokyo have for some time past NO. 2308, VOL. 92] noticed indications of unrest in the vast crater of Asama, in central Japan, but it is on the fissure of Satsuma, at the extreme south of the archipelago, that the recent disasters have occurred. Of the four great volcanoes on this fissure the most northern, Kirishima (5538 ft. high), burst into eruption some weeks ago, and the outburst became paroxysmal simultaneously with that of Sakurajami. Sakurajami is an island mountain in the Gulf of Kagoshima, rising to the height of $3743 \mathrm{ft}$, with three apparently extinct craters eight miles distant from the town of Kagoshima. The only indications of volcanic activity up to the time of the recent outburst were some hot springs and a few steam jets appearing on the southern crater after heavy snow or rain. The island and adjoining portion of Kiusiu have long been famous for their fertility.

There may be some truth in the tradition that the volcano of Sakurajami was formed by a great eruption in 796 A.D., and it is asserted that no considerable outburst took place from it between that date and 1779 , when an eruption accompanied by a great seismic sea-wave covered the five miles of water between the island and Kagoshima, so that people could walk across it. The general rule that a quiescence of long duration is followed in volcanoes by an eruption of exceptional violence is illustrated in this case, for the dormancy of the volcano after the outburst of I779 has lasted I35 years.

Warning of impending disaster was given on January io by loud rumblings and earthquake shocks, and these increased in frequency and violence, so that on the following day they were noted as taking place at intervals of three to five minutes. On the morning of January is a rent was seen to be formed about one-third up the mountain side, a column of steam and dust being thrown up to the height of I, ooo ft., and this was followed by the appearance of three other fissures. In spite of assertions to the contrary, it is doubtful if lava flowed from either of these rents. Forty minutes later, eruption took place from one of the summit craters, a column rising to the estimated height of $2700 \mathrm{ft}$.

This outburst was accompanied by an earthquake felt over the whole island of Kiusiu, and a seismic wave on the sea, while volcanic dust fell on Kagoshima, where it accumulated to depths variously estimated from 2 to $\mathrm{I}_{5} \mathrm{ft}$.; the dust reached Nagasaki, roo miles away, on January I 3 , and Tokyo and Yokohama, 6oo miles off, on January 14. On this last date it is said that "the west side of the volcano blew out," and this was accompanied by another earthquake and seismic sea-wave. Whether this last occurrence indicates the formation of a larger fissure or a great new crater is not clear, and, although decline of the volcanic action is reported, it may be doubtful if the eruptions are yet really at an end.

(Telegrams from Japan, since the above was written, indicate that doubt as to the cessation of the eruptions was justified.) 